vestigation of children who were mentally retarded, but in the family studies that followed it soon became apparent that there were at least an equal number of children with the biochemical abnormality who were completely normal. Some of the histidinaemic children were mistakenly thought to have phenylketonuria because their urine reacted with ferric chloride or Phenistix in a similar way to the urine from children with that disease. It became evident that this reaction was not due to the presence of phenylpyruvic acid in the urine but to the corresponding metabolite of histidine -namely, imidazolepyruvic acid.

The diagnosis of histidinaemia is rarely suspected on clinical grounds and is usually found on routine investigation of mental retardation, a histidine spot being found on urinary amino-acid chromatography. Confirmation of the diagnosis is made by finding a high plasma level of histidine (greater than $5 \mathrm{mg} / 100 \mathrm{ml}$ ) and a low or absent skin histidase activity. Further testing will show an abnormal response to a histidine load and a low level of urocanic acid in the sweat.

Neville and colleagues review 42 cases of histidinaemia including the seven of their own. They have excluded other reported cases on the grounds that they have insufficient documentation for strict comparison. Sixteen of the 42 patients were completely normal, while a further 12 had an intelligence quotient in the low normal range (80-100) with behaviour problems, seizures, or speech delay, though present evidence is against a specific speech defect in histidinaemia. Only 14 of the 42 cases were mentally retarded; 6 of these had seizures while 3 had an early infantile psychotic disorder (autism), which in 2 may have followed a respiratory infection.

The incidence of histidinaemia is not known with certainty. H. L. Levy² found it to be 1 in 14,000 in a neonatal screening programme, while $\mathrm{D}$. N. Raine ${ }^{3}$ has found it to be as common as phenylketonuria ( 1 in 10,000). If histidinaemia is as common as these figures suggest, it is apparent that the great majority of people with it go unrecognized, presumably because they are "normal" and do not present for investigation. Indeed Neville and colleagues wonder if histidinaemia as such is more than an incidental finding in patients who are retarded, though they do suggest that superimposed infections and seizures may play a part in determining whether brain damage occurs.

The inheritance of histidinaemia is that of an autosomal recessive condition, each parent carrying the gene and there being a one-in-four chance of any child having the disorder. Investigation to determine whether an individual is a heterozygote cannot give the $96 \%$ discrimination rate of heterozygote detection in phenylketonuria. ${ }^{3}$ Some heterozygotes have a low skin histidase level, and histidine loading tests may detect others. B. N. La $\mathrm{Du}^{4}$ has found that the urinary excretion of formiminoglutamic acid (figlu) after a histidine load is low and it is possible that the urinary histidine/figlu or hist dine/urocanic-acid ratio after a histidine load may be a more sensitive means of detecting heterozygotes.

Detary treatment of histidinaemia is possible with a low histidine diet, but it is not yet known whether this will change the prognosis for histidinaemic children. It is difficult to know whether to treat an infant who is found to have histidinaemia on neonatal screening, but in the present state of knowledge there is no ethical reason to treat those so discovered. The wisest course would seem to be to conduct a controlled trial using a low-histidine diet in half the cases on the understanding that as soon as one course of action was undeniably better than the other the trial would be stopped. It would be interesting to know if breast-fed children with histidinaemia fare any better than those fed with cow's milk, who receive three times more histidine in their diet.

1 Neville, B. G. R., Bentovim, A., Clayton, B. E., and Shepherd, J., Archives
of Disease in Childhood, 1972, 47, 190.
2 Levy, H. L., "B.ochemical Detection of Genetic Diseases," paper read at
the Fogerty International Conference on Ethical Problems in Human
Genetics. National Institutes of Health, Bethseda, Maryland, 1970.
3 Raine, D. N., British Medical fournal, 1972, 2, 329.
4 La Du, B. N., "Histidinemia," in The Metabolic Basis of Inherited Disease,
3rd edn., p. 338., ed. J. B. Stanbury, J. B. Wyngaarden, and D. S.
Fredrickson. New York, McGraw-Hill, 1972.

\section{What is Overpopulation?}

The Secretary of State for Social Services, Sir Keith Joseph, got quite a hammering from the Select Committee on Science and Technology when he failed to produce a population policy for their inspection. ${ }^{1}$ And the committee declared it was "astonished" that he apparently had no plans or policy for relating family planning services to population size or trends. But the Minister was doing little more than state the obvious when he told the committee that until the Government decides there will be a population policy Ministers cannot act as though there was one. Neither the Health Department nor any Government has ever hinted at the outlines of a policy on "population size or trends."

Even to infer the trends in Great Britain from the present facts is apt to be like dodging after a hare. Estimates of the population in future decades swing up or down almost annually in accordance with changes in birth rates, death rates, immigration, and emigration. But what does need attention, as Sir Keith pointed out, is the large number of "regretted pregnancies." Many of these result in illegitimate births, of which there were some 65,000 in 1970 in England and Wales, practically twice the figure for 1950 and one and a half times the figure for $1960 .^{2}$ Many more occur within marriage, the total being estimated at some quarter of a million annually according to Sir Keith. While the decision to have children is unlikely to be a wholly rational affair, at least the medical profession, aided by the Department of Health, has a role in helping to prevent the birth of children whose conception is regretted even though the babies themselves often come to be in a greater or less degree accepted. But what that role needs is much more thought than it has received, and it is welcome news that the Department of Health is carrying out a study-described by Sir Keith as "comprehensive" - of the effects of family planning services on reducing the number of regretted pregnancies.

Anxious about the possible dangers to people's health from overpopulation, the Representative Body of the B.M.A. at its recent meeting in Southampton instructed the Council to prepare a report for discussion next year and urged the Government to adopt a "positive policy" on this problem. ${ }^{3}$ The representatives were certainly reflecting the opinion of many other people in this country, one of the most densely populated in the world, that the size of its population ought to become a subject of State policy, though this has never so far been accepted. But care is needed over the aims of a specifically medical study of a subject which, as Sir Ronald Tunbridge reminded the meeting, involves much more than medicine. Though the term overpopulation is common coin, few stop to think what the prefix "over" means. Many people, perhaps the majority, like living in crowded cities. 
When does a populated place become overpopulated? By what criteria is it judged to be so? These are questions that are rarely asked or answered in precise terms. A clear discussion of them from the medical profession is overdue.

1 Fifth Report from the Select Committee on Science and Technology

2 Registrar General's Statistical Review of England and Wales for the year 1970, Part 2, Tables, Population. London, H.M.S.O.,

3 British Medical fournal Supplement, 1972, 3, 103.

\section{Medical Radiations}

Next to the natural background, which we cannot alter, medical radiology is the largest source of radiation to the population in developed countries. The incidental dangers to staff and patients are generally difficult to measure-or even to recognize-but their control is important, if only because doctors should keep their own houses in order before pronouncing, as they are often expected to do, on fall-out, nuclear power, and other hazards of modern life.

The Code of Practice, issued by the Health Departments for the guidance of hospital authorities and individual radiation users, now appears in a new edition. ${ }^{1}$ As in earlier formulations, the guiding principle is that radiation doses to staff and patients should be no greater than is necessary to produce a satisfactory result. No significant changes are proposed in the maximum permissible dose levels (which few radation workers ever approach) or in the other protective measures defined at the last revision in 1964, but additional administrative measures are recommended. Patients discharged from hospital while carrying substantial amounts of radioactivity will in future be supplied with instruction cards dealing with radiation and contamination hazards. Advice is given on the procedure (already used by some employing authorities) for deciding whether particular classes of radiation workers should carry film badges or whether their safety is adequately maintained by regular environmental monitoring. More detailed arrangements for record keeping and for annual reviews of safety are also prescribed.

The British way of dealing with radiation hazards is a characteristic compromise between individual freedom and legislative restriction, but it is undoubtedly effective, whether judged by the reduction of doses to staff and patients or by the satisfied state of public opinion. This success story might usefully be studied in relation to the contentious problems created by more recently recognized forms of environmental pollution.

\section{Code of Practice for the Protection of Persons against Ionizing Radiations arising from Medical and Dental Use, 3rd edn. London, H.M.S.O., 1972 .}

\section{Spongy Change in the Brain}

"Spongy change" is the description given to the distinctive appearance of the brain in a variety of neurological diseases. The terms "spongiform encephalopathy" and "status spongiosus" are also used. The appearance may be suffciently gross to be visible to the naked eye, but the terms are applied as well to the microscopic appearance of the scattered spaces which are presumed to result from the loss of brain substance. Sometimes only one cell type or cell component is picked out. F. Seitelberger's definition of status spongiosus as "an alteration of the central nervous tissue in the form of a spongy loosening presenting a threedimensional network of fibrillar tissue components and appearing as a system of vesicular cavities filled with fluid"1 is somewhat stylized. It is also an extreme definition of a process which may be both fragmentary and focal.

Spongy changes can be observed in a variety of aetiologically different diseases such as Alzheimer's disease, neuro-axonal dystrophy, certain neuronal lipidoses, Hallervorden-Spatz disease, arteriosclerosis, hypertension, and some post-infectious, post-inflammatory syndromes. ${ }^{1}$ The exact relationship with derangements of intracellular structure and metabolism as seen primarily in cerebral oedema has been widely debated. ${ }^{2}$ Concurrently with the spongy change, however, other cellular reactions also occur-for instance, glial proliferation, sometimes with formation of fibrillary astrocytes, loss of myelin, phagocytosis, and loss of cells Though these striking changes have prompted speculation about their causes, the study of them so far has done no more than point to a classification of degenerative diseases.

A recent paper ${ }^{3}$ reporting so-called "spongiform encephalopathy" in six patients dying with Jakob-Creutzfeldt disease is a reminder of how, in this disease, a transmissible agent has been detected. ${ }^{4}$ The classical histological features of viral encephalitis with inclusion bodies are lacking, and at present the precise pathogenesis of this and other supposed slow infective encephalopathies is unknown. It is not known whether the agent is a virus in the accepted sense, and no surprise, therefore, that treatment with idoxyuridine (effective only against DNA viruses) has been unsuccessful.

By contrast there is a rare progressive degenerative disease in infants, known as spongy degeneration of the brain, or Canavan's disease, 56 whicn is genetically determined as an autosomal recessive condition, mainly in patients of Jewish extraction. An inborn metabolic error is almost certainly the cause of this disease, which presents at about the sixth month, with arrest of mental development and progressive loss of skills. Against a background of hypotonia extensor spasms occur, and though progressive enlargement of the head may be the result of obstructive hydrocephalus in some patients it is more commonly due to true megalencephalus of a degree sometimes sufficient to cause separation of sutures. Optic atrophy occurs early, but, though the rest of the clinical picture closely resembles the early stages of classical Tay-Sachs disease, neither the characteristic enzymic abnormalities nor a cherry red spot at the macula have ever been reported at any stage of the disease. Gradually the clinical picture is dominated by decerebration with some dystonic features, and most patients die during the second year of the affliction. There are no pathognomonically helpful investigations in life-in particular, spinal fluid is usually normal. At necropsy the brain has the consistency as well as the appearance of a sponge, particularly the white matter. These changes may occur throughout the neuraxis, but nerve roots are spared. Tiny cavities are concentrated in deeper structures round small blood vessels, and vacuoles develop in cytoplasm of both neurones and glia.

These particular changes have been considered to be specific, but essentially similar changes may occur in hyperglycinaemia, ${ }^{7}$ arginosuccinic acidaemia, ${ }^{8}$ homocystinuria, ${ }^{9}$ 